\title{
O Processo de Evolução de Regras de Gamificação para Emergir uma Inteligência Coletiva
}

\author{
Adilson Ricardo da Silva, Mariano Pimentel \\ Universidade do Estado do Rio de Janeiro (UNIRIO) \\ Avenida Pasteur, 458 - 22.290-240 - Rio de Janeiro - RJ - Brasil \\ \{adilson.dasilva, pimentel\}@uniriotec.br
}

\begin{abstract}
The aim of this paper is to present the evolution in the process of creating rules in an online education environment for the emergence of a collective intelligence. In this paper, I present the evolution of the rules in an online environment. The initial research's objective was to get the engagement from the gamification, which was very efficient. This research was divided in three cycles and, at the end of each cycle, the evaluation of the rules allowed its evolution. This research used the epistemological paradigm Design Science Research (DSR), a way of doing science that has as one of its products an artifact, in this case, the rules (a model) and its application (an instantiation).
\end{abstract}

Resumo. O objetivo deste artigo é apresentar a evolução no processo de criação de regras em um ambiente de educação online para emergir uma inteligência coletiva. Neste artigo apresento a evolução das regras em um ambiente online gamificado. $O$ objetivo inicial da pesquisa era obter o engajamento a partir da gamificação, o que se mostrou bastante eficiente. A pesquisa foi dividida em três ciclos e, ao final de cada ciclo, a avaliação das regras permitiu sua evolução. Esta pesquisa utilizou o paradigma epistemológico Design Sicence Research (DSR), uma forma de fazer ciência que tem como um de seus produtos um artefato, neste caso, as regras (um modelo) e sua aplicação (uma instanciação).

\section{Introdução}

Comunidades online têm participação desigual, cada participante tem seu próprio perfil de interação com o grupo. Nielsen (2006) apresenta uma regra que se aplica à maioria das comunidades online; na pesquisa, esse autor divide os participantes em três grupos: os participantes extremos que representam $1 \%$, os participantes eventuais que representam $9 \%$ e os $90 \%$ restante são classificados como meros observadores, como pode ser observado na Figura 1. 


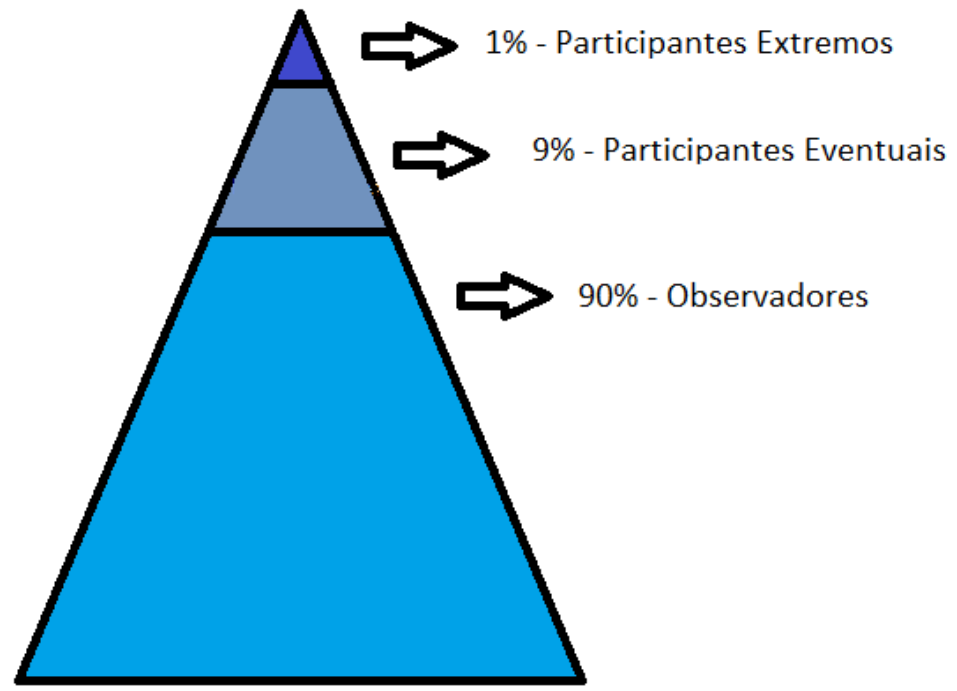

Figura 1. Regra 90-9-1 de Nielsen

Nielsen conclui, em sua pesquisa, que todas as comunidades online têm esses três perfis de participantes, mas as proporções da pirâmide podem ser alteradas; por exemplo, a wikipedia americana obedece à regra 99,8-0,2-0,003, ou seja, enquanto $99,8 \%$ dos participantes são meros observadores, apenas $0,003 \%$ contribuem efetivamente na plataforma (Nielsen, 2006).

Nas comunidades educacionais online a participação desigual também ocorre e, por este motivo, o foco de nosso grupo de pesquisa é encorajar a interação dos alunos observadores, pois, apenas desta forma, contribuirão para a formação dos seus pares e também para sua própria formação (Silva et. al, 2016).

Lampe e colaboradores (2010), ao falarem sobre a motivação de um participante em continuar contribuindo com a comunidade online, afirmam que o motivo que leva uma pessoa a participar de um grupo virtual pode ser diferente do motivo que a levou a entrar nessa comunidade, dessa forma, a discussão dos autores está nas formas de como manter essas pessoas motivadas e engajadas na participação.

A gamificação surge, então, como uma possibilidade de aumentar o engajamento dos participantes, um requisito essencial para a continuidade de uma comunidade online (Classe e Araujo, 2015).

Ao utilizar os elementos universalmente encontrados em jogos, a gamificação pretende alcançar envolvimento, motivação e engajamento dos participantes (Fardo, 2013), com isso, podemos gerar nos integrantes da comunidade online o mesmo sentimento que teriam ao participar efetivamente de um jogo.

Esta pesquisa não propõe o desenvolvimento de um sistema de inteligência coletiva, mas a utilização dos princípios de colaboração para gerar regras de gamificação mais robustas para aplicação em um ambiente online e, enfim, emergir uma inteligência coletiva

As Seções seguintes apresentam os subsídios necessários para que pudéssemos realizar esta pesquisa. A Seção 2 apresenta um referencial teórico com os conceitos de gamificação e inteligência coletiva. $\mathrm{Na}$ Seção 3 apresentamos a Desing Science 
Research (DSR), paradigma de pesquisa utilizado para a condução deste estudo, e a Design Science Research Methodology (DSRM), um método científico para a realização de pesquisas em DSR. A Seção 4 e suas subseções contêm os ciclos desta pesquisa que terão seus achados apresentados na Seção 5. A Seção 6 apresenta a conclusão deste artigo com limitações encontradas e sugestões de trabalhos futuros.

\section{Referencial Teórico}

Esta pesquisa utilizou-se dos dois conceitos apresentados na introdução deste artigo, a Inteligência Coletiva e a Gamificação. Esses conceitos serão apresentados nas Seções seguintes.

\subsection{Inteligência Coletiva}

Pierre Lévy (2014) apresenta uma das definições mais citadas ${ }^{1}$ sobre a inteligência coletiva: "É uma inteligência distribuída por toda a parte, incessantemente valorizada, coordenada em tempo real, que resulta em uma mobilização efetiva das competências ... A base e o objetivo da Inteligência Coletiva são o reconhecimento e o enriquecimento mútuos das pessoas...” (p. 29).

A inteligência coletiva emerge quando os sujeitos chegam a uma decisão após uma ou mais execuções do ciclo "ideia - desentendimento - contra-ideia - acordo" (Gunasekaran et al., 2013).

A coletividade e seus objetivos são uma possibilidade para o surgimento de uma inteligência coletiva. Alguns autores, como Bell (2009), chamam a inteligência coletiva de "a nova inteligência artificial", pois algumas aplicações fazem o uso das informações oriundas dos participantes para alimentar sua base de dados e, assim, gerar conhecimento e promover a inteligência coletiva.

Embora a Inteligência Coletiva não necessite do apoio das Tecnologias de Informação e Comunicação, o surgimento de novas tecnologias aumentou potencialmente os eventos de Inteligência Coletiva. Um conceito para a criação de sistemas que promovem a colaboração é a WEB 2.0 que possui, dentre seus oito principais padrões, um que utiliza a Inteligência Coletiva criando "uma arquitetura de participação que usa algoritmos e efeitos de rede para produzir um software que melhora à medida que mais pessoas o utilizam" (Musser, 2007). As novas tecnologias que permitem a conectividade entre os sujeitos potencializam o crescimento da Inteligência Coletiva (Diplaris et al., 2010).

Como exemplo de ambientes de Inteligência Coletiva podemos citar a Wikipédia, um ambiente colaborativo onde os participantes podem editar conteúdos sobre diversos assuntos. O waze $^{2}$, normalmente apresentado como uma aplicação gamificada, foi classificado também como um ambiente de Inteligência coletiva por Nishi e colaboradores (2012), pois tem sua base alimentada colaborativamente e utiliza estas informações em benefício da ferramenta.

\footnotetext{
${ }^{1}$ Em pesquisa realizada no Google Acadêmico em 26/03/2017, essa obra possui 3.801 citações em sua versão em português, 2.256 em sua versão em inglês e 1.464 citações na versão em francês.

${ }^{2}$ https://www.waze.com/pt-BR
} 


\subsection{Gamificação}

O termo gamificação foi utilizado pela primeira vez em 2008 e, desde então, diversos autores tentaram cunhar uma definição para o termo. A mais popular está no trabalho de Deterding e colaboradores $(2011)^{3}$ que definem a gamificação como "o uso de elementos de game design em contextos de não-jogo".

Outra definição bastante popular é a de Zichermann e Cunningham (2011) ${ }^{4}$ que afirmam que gamificação é o "processo de game-thinking ${ }^{5}$ e mecânicas de jogos para engajar usuários e resolver problemas”.

Nessa pesquisa a definição utilizada é a de Deterding e colaboradores (2011), pois entendemos que é mais abrangente e que não está limitada às mecânicas de jogo para definir um ambiente gamificado.

Em diversas outras definições de gamificação um termo que sempre está presente é "engajamento", esta é uma palavra-chave quando pensamos em gamificação e essa ideia de manter os usuários engajados vem dos jogos, pois costumamos classificar os melhores jogos como os mais "viciantes", mais envolventes e que costumam consumir muitas horas de seus jogadores. Para conseguirmos este engajamento voluntário, devemos ter regras bem elaboradas, um sistema eficaz de feedback e metas bem definidas (Busarello et al., 2014).

Além do engajamento, outra palavra-chave na gamificação é a "recompensa", pois cativa o participante. Isso é muito comum em programas de fidelidade de diversas empresa, pois mantém usuários consumidores frequentes. Entretanto, oferecer "prêmios em dinheiro ou 'do mundo real' tendem a atrair o tipo errado de audiência", portanto uma boa estratégia é que os usuários possam "consumir" seus ganhos dentro do próprio ambiente (Santos Jr, 2014).

Um exemplo bem-sucedido de gamificação é o foursquare ${ }^{6}$, uma aplicação para smartphones que, entre outras funções, implementa a busca e recomendação de lugares, além de publicar dicas e avaliações de locais. Inicialmente o foursquare tinha como sua principal funcionalidade os "check-ins" e ao utilizar esta função o usuário ganhava pontos e poderia alcançar alguns badges, um objetivo de muitos usuários era se tornar o "prefeito" do local. Atualmente essa última funcionalidade pertence ao aplicativo swarm, também do grupo foursquare.

A abordagem PBL (Points, Badges and Leaderboard) é a mais comum ao se implementar um ambiente gamificado, Werbach e Hunter (2012) a chamam de "PBL Triad". Embora muito popular, esta abordagem apresenta diversas limitações. Os pontos motivam a contribuição, as ações no ambiente possuem, normalmente, uma pontuação associada e a execução de tarefas gera pontos aos participantes. Os badges de conquista mostram a evolução do participante, podem ser considerados uma versão mais elaborada dos pontos, uma associação dos badges com os jogos seria a "mudança de nível". O

\footnotetext{
${ }^{3}$ Em pesquisa realizada no Google Acadêmico em 26/03/2017, essa obra possui 2.774 citações.

${ }^{4}$ Em pesquisa realizada no Google Acadêmico em 26/03/2017, essa obra possui 1.265 citações.

${ }^{5}$ Uso da abordagem de jogos para resolver problemas e criar melhores experiências (Marczewski, 2015)

${ }^{6} \mathrm{https}: / /$ pt.foursquare.com/
} 
último conceito da tríade é a lista de classificação, ou ranking, é um mecanismo de feedback muito utilizado em jogos. É um item controverso, pois, ao servir como fator motivador para os que estão nas primeiras posições, pode causar a desmotivação dos que estão na parte inferior da lista (Werbach e Hunter, 2012).

A gamificação não deve ser confundida com a criação de um jogo. $\mathrm{O}$ resultado de um ambiente gamificado não é um jogo, pelo contrário, é um não-jogo. Entretanto esse não-jogo deve criar no participante uma atmosfera que o faça lembrar do prazer de jogar (Santos Jr, 2014).

\section{Design Science Research (DSR)}

A pesquisa que gerou este artigo foi concebida a partir do paradigma epistemológico $\mathrm{DSR}^{7}$, uma abordagem apresentada recentemente e que vem se popularizando em algumas áreas, principalmente em Sistemas da Informação (SI), área em que as pesquisas objetivam produzir conhecimento que possibilite o desenvolvimento de soluções tecnológicas para problemas importantes que atendam às diversas áreas de negócios (Hevner et al., 2004).

A DSR propõe a construção de conhecimento a partir do projeto de artefatos que resolverão um problema em um determinado contexto. Outra característica importante das pesquisas em DSR é sua estrutura, como as pesquisas ocorrem. Um artefato que não é construído com base em conjecturas teóricas e que não é avaliado com rigor científico não pode ser considerado pesquisa científica (Pimentel e Filippo, 2016). O uso de teoria para construir um artefato e um método para avaliação deste artefato faz com que pesquisas em DSR sejam, normalmente, executadas em ciclos, a cada ciclo o artefato é evoluído com a avaliação executada no ciclo anterior. O grupo de pesquisa que participo esquematizou, com base em Hevner e Chatterjee (2010), este conceito de ciclos de pesquisa para evolução do artefato, que pode ser observado na Figura 2.

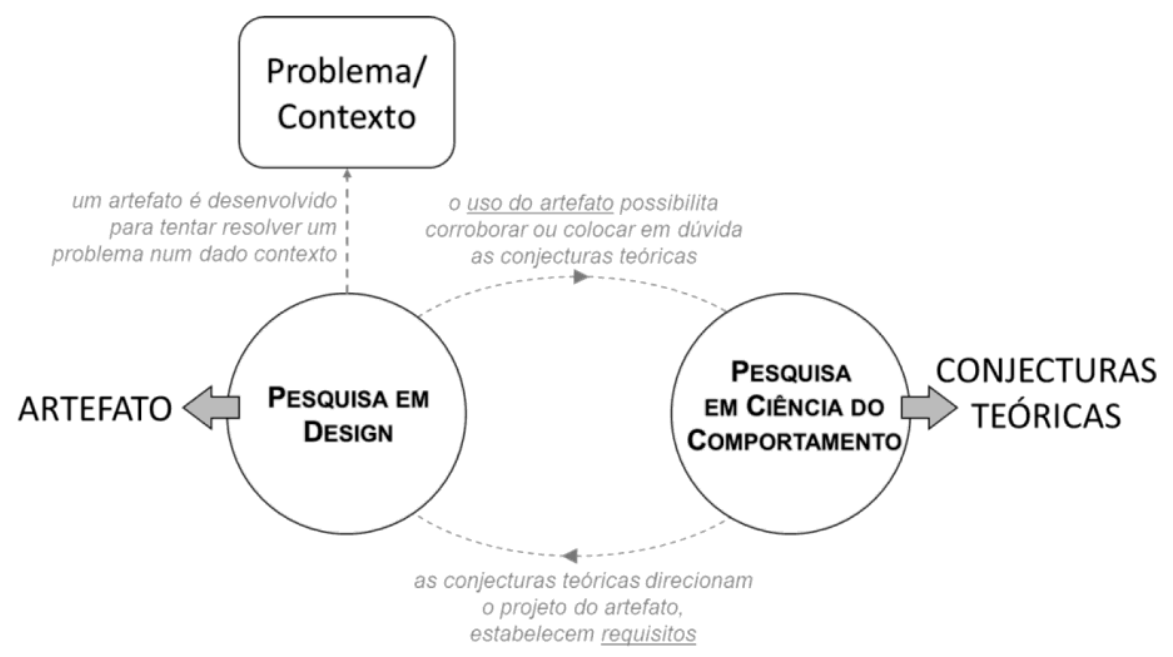

Figura 2. Ciclos em Design Science Research (adaptado e traduzido de Hevner e Chatterjee, 2010)

\footnotetext{
${ }^{7}$ Embora alguns autores prefiram traduzir o termo Design Science Research, nesse artigo, manterei os termos em inglês para evitar qualquer problema decorrente de discordância na tradução.
} 
A definição de artefato, tem sido atualizada conforme ocorre a evolução da DSR. Simon (1996) apresenta o conceito de artefato como sendo tudo o que é "não-natural" ou "artificial" no sentido de ser feito pelo homem; esse conceito é muito amplo. Peffers e colaboradores (2008) restringiram um pouco afirmando que um artefato é algo projetado para alcançar um determinado objetivo. Entretanto, esta definição ainda parece ser muito ampla. Vaishnavi e Kuechler (2015) restringiram um pouco mais este conceito apresentando oito tipos de artefatos: Construto, Modelo, Framework, Arquitetura, Princípio de Projeto, Método, Instanciação e Teorias de Projeto.

Vários métodos para se fazer pesquisa em DSR foram propostos e, todos eles têm algumas atividades em comum, como a definição do problema; a revisão da literatura ou a busca por teorias existentes; apresentação de sugestões de possíveis soluções; desenvolvimento e avaliação das soluções propostas (do artefato); decisão sobre a melhor solução; e a comunicação dos resultados para a comunidade científica (Dresch et al., 2015).

Nesta pesquisa utilizei Design Science Research Methodology (DSRM), um método apresentado por Peffers et al. (2008) que possui, atualmente, 2.281 citações no Google Acadêmico (pesquisa realizada em 26/03/2017). Este método é composto de seis passos e começa com a identificação do problema e a motivação da pesquisa (importância, utilidade da pesquisa).

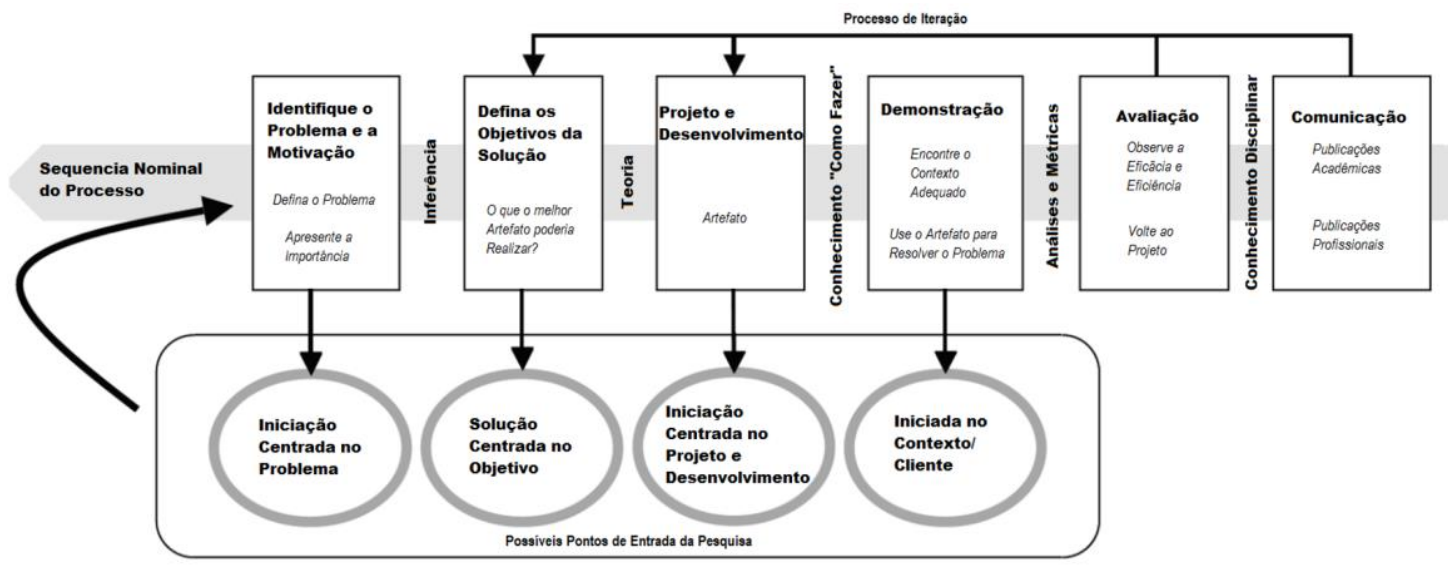

Figura 3. Método de Pesquisa DSRM (Traduzido de Peffers et al., 2008)

A descrição detalhada do método será apresentada na Seção 4.2, quando será descrito o segundo ciclo da pesquisa.

\section{Ciclos de Pesquisa}

A execução desta pesquisa ocorreu em três ciclos. Entre um ciclo e outro as conjecturas teóricas foram revisitadas para ajustes e os artefatos foram alterados para contemplar os resultados da avaliação ocorrida no ciclo anterior.

Os ciclos descritos nas Seções seguintes apresentam a evolução da pesquisa e seguirão a metodologia apresentada resumidamente na Seção 3. 


\subsection{Gamificação versus Aproveitadores}

Essa pesquisa começou na avaliação dos resultados de um estudo de caso proposto em uma turma presencial em uma Universidade do Rio de Janeiro. Eu assumi que, nesta pesquisa, este foi o primeiro ciclo; embora os seis passos de um ciclo DSRM não tenham sido executados em sua totalidade. Portanto, o início desse ciclo se dá no passo cinco do método científico utilizado nessa pesquisa.

O estudo de caso proposto na turma tinha o objetivo de aumentar a participação dos alunos nas atividades online propostas pelo professor da disciplina. O professor criou um grupo no Facebook com a intenção de participação dos alunos com contribuições com assuntos relevantes para a disciplina, mas a adesão era pequena e o grupo funcionava como um mural de avisos da disciplina.

$\mathrm{Na}$ proposta de gamificação do grupo foram apresentadas aos alunos as ações que gerariam pontos e bonificações para os participantes. Após este ato passou-se a computar os pontos dos alunos pelas ações relacionadas na tábua de pontuação.

Neste momento a comunicação no grupo tornou-se tumultuada e caótica, com alunos fazendo comentários em postagens antigas com o único objetivo angariar pontos. Começaram a surgir comentários vazios, sem informação útil, floods, comentários com uma palavra ou uma letra. A esse comportamento demos um nome: Aproveitadores.

Definimos estes aproveitadores como as pessoas que se aproveitaram da fragilidade das regras para benefício próprio, ou seja, apenas para "ganhar a competição". Este comportamento se assemelha aos killers, presentes na taxonomia proposta por Bartle (1996).

Ao avaliar os artefatos deste primeiro ciclo, chegamos à conclusão que a gamificação aumenta a participação, mas que as regras precisam ser repensadas para o atingimento de um melhor resultado.

\subsection{Gamificação + Inteligência Coletiva para Inibir os Aproveitadores}

Esta Seção apresenta a execução do segundo ciclo desse estudo e, concomitantemente, detalha a metodologia científica utilizada na pesquisa, a DSRM, apresentada resumidamente na Seção 3 .

Esse ciclo seguiu os seis passos proposto por Peffers e colaboradores (2008). De fato, o primeiro passo não faz parte da iteração, como se pode ver na figura 3 , pois é onde ocorre a identificação do problema que motivou a pesquisa que, em tese, não se altera. Mas para apresentar a metodologia de forma didática, apresentarei o primeiro passo do método.

O problema que essa pesquisa tentou resolver foi a baixa participação nas atividades online em uma disciplina presencial. Nesse ponto também foi identificada a importância da pesquisa: baixa participação em atividades online. A DSRM apresenta a relevância desse item, pois é uma forma de conferir relevância à pesquisa. Esse momento da pesquisa é importante, pois o pesquisador identifica a necessidade da pesquisa. Dresh e colaboradores (2015) classificam como necessária uma pesquisa que alia o rigor teórico-metodológico à sua utilidade prática para a sociedade (relevância). 
No segundo passo passamos a pensar no melhor objetivo da solução. Como este ciclo é a evolução de um ciclo anterior, o foco está no resultado da avaliação dos artefatos já produzidos e que podem evoluir para a resolução do problema. A pergunta que precisamos responder foi: como o artefato pode evoluir para inibir o comportamento de aproveitadores?

Chegamos à conclusão que deveríamos alterar as regras de pontuação e, para surgir a inteligência coletiva, as regras precisavam ser colaborativas, ou seja, não bastaria a ação do sujeito para que este recebesse recompensa, a ação dele deveria estar associada à ação de outro sujeito, desta forma, a interação seria recompensada e as mensagens sem interação não teriam pontuação na gamificação.

O terceiro passo é para projetar e desenvolver o artefato com o objetivo de resolver o problema proposto no passo um. Com as ideias do passo anterior, pensamos em como as regras poderiam evoluir para aumentar a colaboração e não termos somente uma competição. Ao final deste passo tínhamos um novo conjunto de regras tanto de pontuação quanto de divulgação para acompanhamento.

Com o novo artefato pronto, fizemos uma nova utilização para avalia-lo. Utilizamos novamente o Facebook para as atividades online em uma turma presencial durante três meses. Os dados foram coletados com o aplicativo netvizz (disponível para qualquer usuário do Facebook), tratados para aplicação das regras e divulgados semanalmente. A alteração na periodicidade da divulgação dos dados para acompanhamento foi uma alternativa para evitar um dos comportamentos dos aproveitadores.

O quinto passo do método DSRM é a validação do artefato, este deve ser observado segundo sua eficiência e eficácia, além de como ele se comporta quando aplicado no contexto em que deveria ser analisado. Para avaliar os artefatos desse ciclo, os participantes foram submetidos a um questionário com algumas perguntas sobre os artefatos e sobre o processo de gamificação aplicado.

Nesse passo concluímos que a participação aumenta com a gamificação e que a inteligência coletiva surgiu com a colaboração identificando corretamente várias mensagens relevantes para o grupo; entretanto, algumas mensagens foram classificadas erroneamente quanto à sua relevância. Percebemos que por usar um sistema de rede social para avaliar o artefato, algumas mensagens de cunho social tiveram um alto grau de interação, o que não havíamos previsto. Nossa intenção era computar apenas as mensagens conectadas à disciplina.

Com isso, a decisão deste passo foi voltar ao passo dois e repensar o artefato. Neste ciclo, o último passo não ocorreu, houve a tentativa de publicação de um artigo, mas como os dados ainda estavam muito inconclusivos, não foi publicado.

\subsection{Gamificação + Inteligência Coletiva + Bate-papo com Reações}

Ao final do segundo ciclo, concluímos que o Facebook como plataforma de aplicação do artefato não seria suficiente para nosso objetivo, pois precisaríamos de customizações que não seriam possíveis. Desta forma houve a proposta de desenvolvimento de um sistema de bate-papo gamificado com reações. 
A proposta de reações no bate-papo surgiu no final de 2015 quando o Facebook implementou os novos botões no seu sistema de rede social ${ }^{8}$. Percebemos que seria válido um sistema de bate-papo inspirado nesses botões. Passamos, então, ao desenvolvimento deste novo sistema. As reações utilizadas foram diferentes do Facebook como pode ser visto na Figura 4.

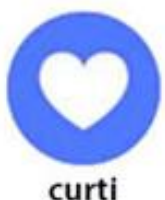

curti

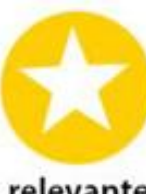

relevante

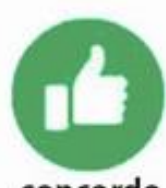

concordo

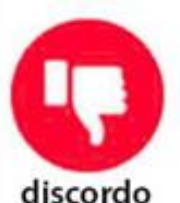

discordo

\section{Figura 4. Reações utilizadas no sistema de bate-papo com reações}

Diferentemente da implementação do Facebook, no nosso sistema de bate-papo não restringimos o uso das reações, um usuário poderia selecionar diversas reações em uma mesma mensagem, inclusive todas. Esta opção serviu para identificarmos como os participantes se comportariam com todos os botões disponíveis e se iriam efetivamente marcar mais de uma reação em uma mensagem.

O desenvolvimento do sistema ocorreu no início de 2016 e foi executada uma sessão para avaliação do artefato. Imediatamente após essa sessão ocorreu um grupo focal onde os participantes avaliaram o sistema, pois estavam tendo contato com a plataforma pela primeira vez. Também depois da sessão os participantes receberam um questionário com perguntas sobre o sistema, sobre a gamificação implementada e sobre a dinâmica de conversar e reagir às mensagens.

Esse ciclo trouxe como contribuição um novo sistema de bate-papo (Figura $5^{9}$ ), desenvolvido utilizando conceitos de gamificação e promovendo a colaboração para criar uma inteligência coletiva.

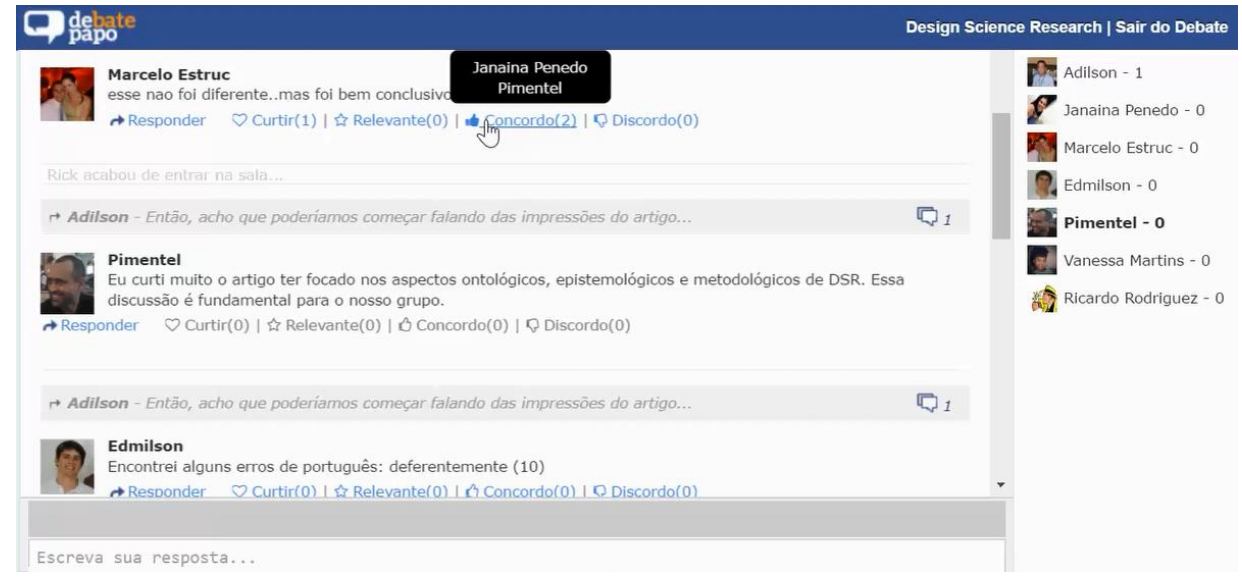

Figura 5. Reações utilizadas no sistema de bate-papo com reações

\footnotetext{
8 http:/www.techtudo.com.br/noticias/noticia/2015/10/facebook-tera-botoes-de-reacao-alem-do-conhecaos-seis-emojis.html

9 Os participantes desta seção de bate-papo responderam a um Termo de Consentimento Livre e Esclarecido e autorizaram a divulgação de suas imagens de perfil, bem como seus nomes reais, permitindo assim também a garantia de expressão da autoria de suas mensagens.
} 
Outra contribuição explícita foi o uso das reações, que parece promissor, mas que carece de novos estudos para percebermos o uso dos participantes.

\section{Achados}

No primeiro ciclo da pesquisa, o achado foi a confirmação da nossa conjectura teórica, que a gamificação promove o engajamento dos participantes. Nessa mesma iteração, também descobrimos que as regras da gamificação precisam ser colaborativas para não gerar apenas o sentimento de competição entre os participantes. Os aproveitadores foram o grande problema nesse momento da pesquisa.

$\mathrm{O}$ segundo ciclo confirmou o achado do primeiro sobre o engajamento proporcionado pela gamificação. O surgimento da inteligência coletiva não foi como esperávamos, não conseguimos inferir com precisão as mensagens relevantes para a discussão no grupo. Mensagens de cunho social dificultaram a identificação das mensagens relacionadas à disciplina.

No último ciclo descobrimos que faz sentido um bate-papo com reações. No grupo focal realizado após a sessão de avaliação do sistema de bate-papo, os participantes confirmaram nossa conjectura teórica. Influenciados pelos sistemas de redes sociais e mensageiros mais populares, a comunicação não-textual passou a fazer parte do nosso cotidiano.

Fato interessante sobre esse achado é que desde o dia 23/03/2017 o Facebook passou a permitir reações em seu sistema de bate-papo, o Messenger ${ }^{10}$ (Figura 6).
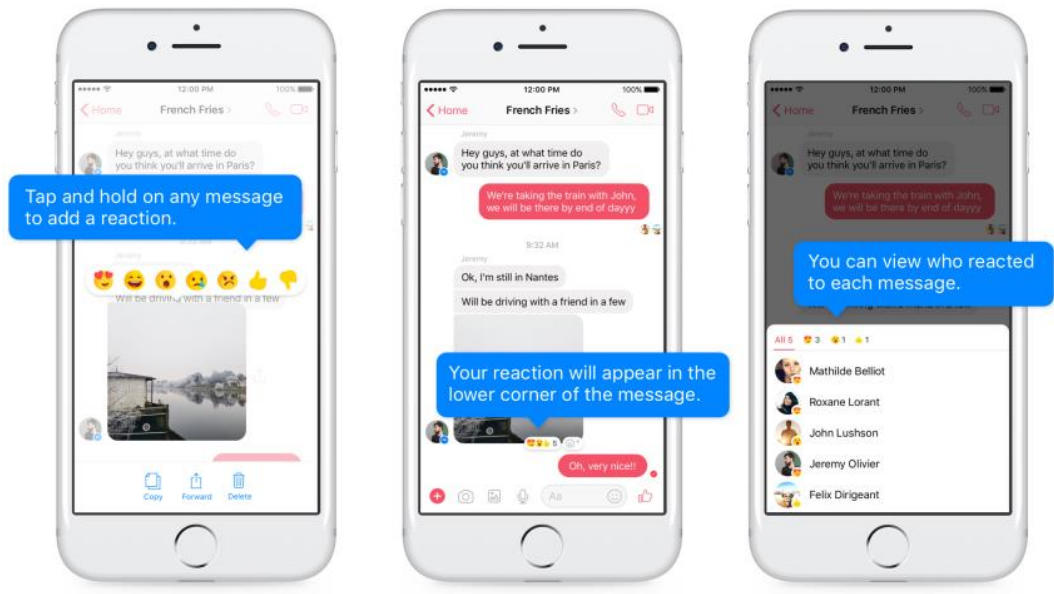

Figura 6. Reações do Facebook Messenger ${ }^{8}$

Um dos motivos da implementação das reações em outras plataformas do Facebook pode ter sido por causa do apoderamento dos usuários do sistema. Com um ano de uso das reações, foram contabilizados mais de 300 milhões de reações às mensagens ${ }^{11}$.

\footnotetext{
${ }^{10} \mathrm{https}: / /$ techcrunch.com/2017/03/23/facebook-messenger-reactions/ (acesso em 28/03/2017)

$11 \mathrm{http}: / / w w w . t e c h t u d o . c o m . b r / n o t i c i a s / n o t i c i a / 2017 / 03 /$ reacoes-no-facebook-agora-sao-mais-importantesdo-que-curtidas.html
} 


\section{Conclusão}

Este artigo apresentou a evolução de uma proposta de gamificação de uma comunidade online. Inicialmente no grupo do Facebook em uma turma presencial foi possível perceber o aumento da participação; entretanto os aproveitadores levaram a comunicação a um estado caótico com postagens sem sentido, comentários e curtidas em mensagens antigas, além de outros problemas comuns em comunidades online.

A evolução das regras e da forma apresentação para o acompanhamento dos participantes no segundo ciclo manteve a participação alta e evitou os aproveitadores. Nesse ciclo observamos o uso da plataforma, ainda que dentro de um grupo educacional, com cunho social, isso foi um problema para a identificação das mensagens relevantes no contexto do grupo.

O desenvolvimento de um sistema de bate-papo com reações tentou desvencilhar o social do acadêmico. Com o participante informando explicitamente quais são, na sua visão, as mensagens relevantes para a discussão.

As reações devem ser estudadas em trabalhos futuros, pois apresentaram boa receptividade pelos participantes da sessão de bate-papo. Devem ser observadas sugestões de novas reações ou até mesmo a implementação de reações mutuamente excludentes.

\section{Referências}

Bartle, R. A. (1996) Heart, Clubs, Diamond, Spades: players who suit muds. Disponível em $<$ http://www.mud.co.uk/richard/hcds.htm>. Acessado em 28/03/2017.

Bell, G. (2009) Building Social Web Applications. 1st Edition. Sebastopol, CA: O'Reilly Media, Inc. 2009.

Busarello, R. I., Ulbricht, V. R., Fadel, L. M. (2014) A gamificação e a sistemática de jogo: conceitos sobre a gamificação como recurso motivacional. In Gamificação na Educação, Fadel, L. M., Ulbricht, V. R., Batista, C. R., Vanzin, T., organizadores. São Paulo: Pimenta Cultural, 2014. 300p.

Classe, T. M., Araujo, R. M. (2015) "Gamificação Para Participação Social Em Processos Públicos: Mapeamento Sistemático” In: Simpósio Brasileiro de Sistemas Colaborativos, páginas 130-137. Salvador. Bahia.

Deterding, S., Dixon, D., Khaled, R. et al., (2011) From Game Design Elements to Gamefulness: Defining “Gamification”. In MindTrek'11, Tampere, Finland, 2011

Diplaris S., Kompatsiaris I., Flores A., et al. (2010) Collective Intelligence in Mobile Consumer Social Applications In 2010 Ninth International Conference on Mobile Business / 2010 Ninth Global Mobility Roundtable

Dresch, A., Lacerda, D. P., Antunes Jr, J, A. V. (2015) Design Science research: método de pesquisa para avanço da ciência e tecnologia. Porto Alegre, Bookman.

Fardo, M. L., (2013) A Gamificação Aplicada em Ambientes de Aprendizagem. In Novas Tecnologias na Educação V. 11, N 1, julho de 2013. 
Hevner, A., Chatterjee, S. (2010) Design Research in Information Systems. In Integrated Series in Information Systems 22, DOI 10.1007/978-1-4419-5653-8_2.

Lévy, P. (1994) A inteligência coletiva: por uma antropologia do ciberespaço. São Paulo: Edições Loyola, 2015 [10a ed.]

Marczewski, A. (2015) Game Thinking. Even Ninja Monkeys Like to Play: Gamification, Game Thinking and Motivational Design (1st ed., pp. 15). CreateSpace Independent Publishing Platform.

Musser, J (2007) Web 2.0 principles and best practices. O'Reilly Media, Inc. Sebastopol, CA.

Nielsen J. (2006) The 90-9-1 Rule for Participation Inequality in Social Media and Online Communities. Disponível em $<$ https://www.nngroup.com/articles/participation-inequality/>, acessado em 26/03/2017.

Nishi, M. K., Chaves, A. P., Steinmacher, I. (2012) Um Sistema Baseado em Inteligência Coletiva para Visualização de Problemas em Vias Públicas. In $I X$ Simpósio Brasileiro de Sistemas Colaborativos, 2012.

Peffers, K., Tuunanen T., Rothenberger M. A. et al., (2008) A design science research methodology for information systems research. In Journal of Management Information Systems (JMIS) 24 (3), pp. 45-77

Pimentel, M., Filippo, D (2016) Desafios para fazer Pesquisa Científica de Qualidade (rigor), Útil (aplicada) e Relevante em Informática na Educação. Notas da palestra proferida no $5^{\circ}$ DesafIE!. Porto Alegre, 7 de julho de 2016. Documento online: $<$ http://www.slideshare.net/pimentelmariano/desafios-para-fazer-pesquisa-cientficade-qualidade-rigor-til-aplicada-e-relevante-em-informtica-na-educao-63798760> acessado em 25/03/2017.

Santos Jr, S. A. (2014) Gamificação - Introdução e conceitos básicos, ebook (disponível em gamificando.com.br, acessado em 01/02/2015)

Simon, H., 1996, The Sciences of the Artificial, 3 ed. Cambridge, MIT Press.

Silva, A.R., Estruc, M., Pimentel, M. (2016) Uso da inteligência coletiva para identificação de mensagens relevantes em um bate-papo gamificado. In Anais do Simpósio Brasileiro de Informática na Educação, 2016.

Vaishnavi, V. K., Kuechler, Jr. W. (2015) Design Science Research Methods and Patterns - Innovating Information and Communication Technology, Second Edition, CRC Press, Boca Raton, FL.

Werbach, K., Hunter, D. (2012) For the Win: How Game Thinking can Revolutionize your Business. Wharton Digital Press. Philadelphia, PA.

Zichermann, G., Cunningham, C. (2011) Gamification by design: Implementing game mechanics in web and mobile apps. O'Reilly Media Inc, Sebastopol, CA 